\title{
INFLUENCE OF CULTURE ON SECONDARY SCHOOL STUDENTS' UNDERSTANDING OF STATISTICS: A FIJIAN PERSPECTIVE
}

\author{
SASHI SHARMA \\ The University of Waikato \\ sashi@waikator.ac.nz
}

\begin{abstract}
Although we use statistical notions daily in making decisions, research in statistics education has focused mostly on formal statistics. Further, everyday culture may influence informal ideas of statistics. Yet, there appears to be minimal literature that deals with the educational implications of the role of culture. This paper will discuss the interaction between statistical cognition and culture, reporting on the effects of culture on secondary students' statistical ideas. It will draw on examples from my work and that of a few others who have studied cultural influences on statistical ideas to explain how statistics is tied to cultural practices. The paper will consider the issues arising out of the literature and offer suggestions for meeting the challenges.
\end{abstract}

Keywords: Statistics education research; Socio-cultural theory; High school students; Cultural context

\section{INTRODUCTION}

The importance of statistics in everyday life and the workplace has led to calls for an increased attention to statistics and probability in the mathematics curriculum (Ministry of Education, 2007; NCTM, 2000; Shaughnessy, 2007; Watson, 2006). Gal (2002) and Schield (2010) suggest that attention to real-world demands should be part of the considerations that guide what gets taught, assessed and valued in the statistics classroom. The use of relevant contexts and drawing on students' experiences and understandings is recommended for enhancing students' understanding of statistics (Tishkovskaya \& Lancaster, 2012). Fiji, too, has produced a curriculum document that gives more emphasis to statistics in primary education. However, probability is introduced first at the secondary-school level.

A number of research studies (Amir \& Williams, 1999; Fischbein \& Schnarch, 1997; Kazima, 2006; Watson, 2006) from different theoretical perspectives (e.g., constructivism) show that students tend to have conceptions about statistics which impact on their learning. However, most of these studies have been carried out in Western countries. Jones, Langrall and Mooney (2007) and Shaughnessy (2007) raised concerns about the lack of research in statistics education outside Western countries. They advocated large and small-scale studies that examined group and cultural differences in students' thinking in decision making and statistical tasks. Indeed, it would be interesting to determine how cultural settings influence students' conceptions of statistics, whether biases and misconceptions discussed in literature are artifacts of Western culture, or whether they vary across different cultures. Moreover, a sensitivity to the cultures of others is needed when teaching mathematics in multicultural classes and when teaching a curriculum that is not indigenously grounded (Greer \& Mukhopadhyay, 2005). While some research (Chiesi \& Primi, 2009; Kazima, 2006; Polaki, 2002) has been undertaken outside Western countries, these studies relate strongly to American or English research and do not focus on how the culture of the subjects may have impacted on their decision-making (Greer \& Mukhopadhyay, 2005). This is surprising because statistics educators can lead the way in this regard. Rossman, Chance and Medina (2006) claim that whereas mathematics

Statistics Education Research Journal, 13(2), 104-117, http://iase-web.org/Publications.php? $p=$ SERJ C International Association for Statistical Education (IASE/ISI), November, 2014 
educators often regard context as an obstacle that can obscure the abstract mathematical ideas at the core of a problem, statistics educators usually recognise that their world is indeed embedded in a context, and maintain that students need multiple opportunities to relate their comments to the context when drawing conclusions.

This paper attempts over three sections to address some of the above issues. The first section discusses some obstacles facing researchers who wish to conduct cultural studies. It considers notions of culture and provides a working definition of culture for this paper. This section will help clarify the purpose and context of my study. The second section reports on the effects of culture on students' statistical thinking. I will draw on examples from my work in Fiji to explain how statistics is related to human culture and tied to cultural practices. In particular, cultural beliefs such as religion, values, language and experiences which strongly affected student thinking will be highlighted. The findings will be compared and contrasted with relevant literature. Although the study is located in Fiji, it can be related to other multicultural contexts. The final section considers the issues arising from the discussion and offer suggestions for meeting the challenges identified. Specifically, suggestions for teaching, assessment and further research are outlined.

\section{CULTURE AND STATISTICS EDUCATION}

Due to the internationalisation and globalisation of mathematics education (Cao, Forgasz, \& Bishop, 2007; Ernest, 2007; Reid \& Petocz, 2007) in the last decades, there has been a growing interest in cultural issues in statistics education. In part, this interest is due to concerns about learners whose cultural context is not Western in the sense of not being part of the mainstream of Western technological and mathematical development (Bishop, 2002). In part it is also due to the developing interest in literature concerning the capacity of statistics teachers to deal with cultural aspects of learning (Cao, Forgasz, \& Bishop, 2007; Lesser \& Winsor, 2009; Nasir, Hand, \& Taylor, 2008; Reid \& Petocz, 2007; Winsor, 2007).

There are several obstacles facing any researcher who wishes to examine issues in statistics education through a cultural lens (Bishop, 2002; Lubienski, 2002). First, because of the specialised nature of academic fields, statistics education researchers might not be familiar with emerging research and perspectives relating to culture and power. Researchers wishing to conduct cultural studies of statistics classrooms need to be grounded not only in statistics education research but also in research from fields such as linguistics, anthropology and sociology. This may be particularly difficult because the perspectives guiding studies of culture in these fields have been both highly debated and shifting (Bishop, 1988; Nasir, Hand, \& Taylor, 2008; Neel, 2011). Scholars have even promoted a cultural difference model in which the language and practices of all students need to be considered in the classroom. Since its earliest conceptualisations, culture has evolved in theory and in practice. However, as with any dialogue on education, scholars mould concepts to align with their specific contexts and disciplines.

\subsection{DEFINITIONS OF CULTURE}

This paper draws on a perspective of culture with roots in Vygotskian learning theory (Vygotsky, 1978). In this perspective, culture can be described as the shared way of living of a group of people. It is used to encompass commonly experienced aspects of the group's lives, such as shared knowledge, backgrounds, values, beliefs, forms of expression and behaviours that may impact classroom interactions (Bishop, 2002; Bourdieu, 1984). This means that the cultural practices that we engage in as we move across everyday, school and professional contexts both shape and constitute our learning. However, this can become a complicated concept in schools, where school and classroom cultures exist within broader cultural contexts (Clark 2001; Meaney, 2002). For some students, home and school cultures may be very different, so they need to operate differently in these contexts; for other students, these cultures may be more compatible (Bourdieu, 1984). 
The above definition of culture resonates with principles of socio-cultural theories combined with elements of constructivist theory which provide a useful model of how students learn statistics. Constructivist theory in its various forms is based on a generally-agreed principle that learners actively construct ways of knowing as they strive to reconcile present experiences with already existing knowledge (Confrey \& Kazak, 2006; von Glasersfeld, 1993). This active construction process may result in misconceptions and alternative views as well as the students learning the concepts intended by the teacher.

From the above ideas, it can be argued that informal statistics is firmly established in common culture. As such, there is a potential for conflict and interaction between the knowledge of statistics and probability which students acquire informally, usually outside school, and the formal knowledge that schools present (Amir \& Williams, 1999; Kazima, 2006). Indeed, in our pedagogical work we may be building models of statistics and probability on a weak foundation.

\subsection{RESEARCH IN STATISTICS EDUCATION}

A significant issue for statistics education is the dilemma of how to investigate and incorporate cultural (out-of-school) statistics in school statistics classrooms in ways that are meaningful to students and that do not trivialise the ideas inherent in cultural practices. Nasir et al. (2008), as part of a study on thinking and learning across contexts, asked college students to solve problems about averages in two ways. In one set of tasks, the problems were framed by basketball practices; in the other, they were given in the format of a typical school mathematics worksheet. The researchers report that some of the subjects demonstrated rich mathematical problem solving strategies in non-school context in a form markedly different from what we typically consider school knowledge. These findings led these researchers to reject the notion of knowledge as independent and hence transportable, claiming rather that it is dependent on context. Similar suggestions have been made by Gal (2002). He questioned the assumption that students who learn to process data in school settings can transfer these skills to interpreting and critically evaluating statistical information in everyday situations. For Gal also, statistical knowledge is contingent upon the context or setting, and this led him to develop a dynamic model of statistical literacy which focuses not only on cognitive skills including critical thinking but also on dispositional aspects such as beliefs, values and attitudes. However, Gal (2002) does not refer to cultural knowledge explicitly in his model.

A number of other research studies from different theoretical perspectives show that students tend to have conceptions about statistics and probability which impact on their learning. Some prevalent ways of thinking which seem to inhibit the learning of statistics and hence have relevance for this paper are discussed below.

Representativeness Kahneman and Tversky's (1972) seminal work illustrated the undue confidence that people have in the reliability of small samples. Their 'hospital problem' asked undergraduate students to decide whether a small hospital, delivering about 15 babies a day, or a large hospital, delivering about 45 babies a day, was more likely to record more than $60 \%$ boys.

According to the researchers, the representativeness heuristic underlies this misconception. People who rely on the representative heuristic tend to estimate the likelihood of events by neglecting the sample size or by placing undue confidence in the reliability of small samples.

Equiprobability People tend to think that symmetrical objects such as coins and dice always produce outcomes which are equally likely. For example, if one tosses two coins, one is more likely to get the outcome one head and one tail than to get, say, two heads. However, many people assume that all outcomes have an equal chance of occurring (Lecoutre, 1992). Lecoutre also found that the equiprobability bias was highly resistant to change.

Beliefs Research (Amir \& Williams, 1999; Fischbein, Nello \& Marino, 1991; Truran, 1994) shows that some students think that their results depend on a force, beyond their control, 
which determines the eventual outcome of an event. Amir and Williams (1999) interviewed 38 students in their first year of secondary school (11-12 years old) about their concepts of chance and luck, their beliefs and attributions, and their probabilistic thinking. Some pupils thought God controls everything that happens in the world while others thought God chooses to control, or not control, anything in the world. There were also beliefs directly related to coins and dice, such as tossing 'heads' with a coin is lucky.

Zimmermann and Jones (2002) studied high school students' thinking and beliefs by confronting them with problems involving two-dimensional probability simulations. Various student beliefs emerged from their analysis of the data. They categorised these into helpful or problematic beliefs. A disturbing finding was that some students believed, albeit to different degrees, that simulation cannot be used to model a real-world probability problem.

All the research discussed above has been done in Western countries. Fischbein et al. (1991) did refer to experiences related to the geographical and cultural environment of the individual and to the particular practice of domains of the individual's life, but the authors did not include these aspects in their findings. In contrast, I used variants of previously-used research tasks to explore Fijian high school students' understanding of statistical literacy. More details about my study are given below.

\section{THE CURRENT STUDY}

The research (Sharma, 1997) was conducted in Fiji, my home country. Overall, it was designed to investigate what ideas students in form five (aged 14-16 years) have about statistics and probability, and how they construct these ideas.

\subsection{BACKGROUND}

Of all South Pacific nations, Fiji is the most diverse country in terms of language and culture. Figures show that Fiji's population is about three-quarters of a million with the two larger groups being ethnic Fijians (50\%) and Fijian Indians (46\%) (FijiGuide, 2014). The majority of the population does not speak English as their first language, although English is the official medium of instruction for teaching and learning. The mother tongue (Fijian or Hindi) is used only for an initial period of instruction (usually about three years) to facilitate the use of English for the remainder of the students' education (Shameem, 2002). Primary schools in Fiji teach classes 1 to 8 (in some cases, classes 1 to 6) whereas secondary schools teach forms 3 to 7 and junior secondary schools teach forms 1 to 4 .

Schools focus on teaching students to pass national examinations. This can lead to teachercentred pedagogies which discourage the independence that can lead to self-directed learning. Fijian parents place great emphasis on the academic achievement of their children, and the students study hard to meet the expectations of their parents. Students often attribute their academic success and failure to their efforts in their studies. The teacher is the authority in the classroom and has the moral responsibility of caring for the students and cultivation of moral values.

\subsection{SAMPLE}

The study took place in a co-educational private secondary school in a rural town. The school roll was about 400, mostly Fijian Indians. The school drew students mainly from rural contributing schools, with the students' families from a farming community. It was a typical high school and the staff were interested in being involved in the research project. The study focused on form 5 students for three main reasons. Firstly, statistics is one of the topics taught at form 5 level (Fijian Ministry of Education, Women, Culture, Science and Technology, 1994). Secondly, this was the age group that I had frequently taught during my teaching career and with which I therefore felt most comfortable. Thirdly, since form 5 students in Fiji do not take any external examinations, it was felt that the class teacher would be free of external constraints and more willing to be involved in the project. 
The sample consisted of a complete class of 29 students aged 14 to 16 years of whom 19 were girls and 10 were boys. According to the teacher, none of the students in the sample had received any in-depth teaching on probability prior to the interviews. Fourteen students participated in the individual interviews. The sample was selected in consultation with the class teacher. This group of 14 was representative of the larger group in terms of abilities and gender.

I spent a week developing rapport with the class: for the first few days, I visited the class with the class teacher and observed the class in action. These observations helped me understand the usual classroom culture so that I could identify any changes during the main study period.

\subsection{TASKS}

The tasks were selected and adapted from those reported by various researchers. They addressed descriptive statistics, graphical representations, probability, and statistical investigations. The appropriateness of these interview tasks for Fijian students was established by checking them with the class teacher and the head of mathematics at the school. In contrast to traditional closed-form questions, students were provided in all tasks with opportunities to explain their thinking and express their opinions.

Three of the six tasks are shown next, and results from them will be described later.

Item 1 - Coin task According to Garfield and Ben-Zvi (2008) there are two major concerns of sampling: sampling representativeness and sampling variability, and both must be understood and carefully balanced in order to understand statistical inference. Given the issues involved in sampling distributions and using contextualised mathematics problems in the curriculum, I used a modified version of Kahneman and Tversky's (1972) task (Figure 1).

Shelly is going to flip a coin 50 times and record the percentage of heads she gets. Her friend Anita is going to flip a coin 10 times and record the percentage of heads she gets.

Which person is more likely to get $80 \%$ or more heads?

Explain your answer.

Figure 1. Coin Task.

Item 2 - Advertisement task In situations such as tossing a coin (a one-stage experiment), the outcomes are said to be equally likely, and the particular one that occurs is purely a matter of chance. The theoretical probability can be based on an analysis of the sample space to determine the likelihood. The advertisement regarding the sex of a baby (Figure 2) explored students' understanding of the equally-likely concept in an everyday context.

"Expecting a baby? Wondering whether to buy pink or blue?

I can GUARANTEE to predict the sex of your baby correctly.

Just send \$20 and a sample of your recent handwriting.

Money-back guarantee if wrong!

Write to ..."

What is your opinion about this advertisement?

Figure 2. Advertisement Task.

Item 3 - Black and white marbles task This problem (Figure 3) was used to explore students' conceptions of proportional reasoning, crucial to a conceptual understanding of probability. It is fundamental to making connections between populations and samples drawn from these populations, and hence provides a basis for statistical inference. 
Meena and Ronit have some marbles. Meena is 10 years old. In her box, there are 10 white marbles and 20 black ones. Ronit is only 8 years old. In her box there are 20 white marbles and 60 black ones. They play a game. The winner is the child who pulls out a white marble first. If both take out a white marble at the same time then no one is the winner and the game has to go on. Ronit claims that Meena has a greater chance of pulling out a white marble because she is older, and more clever.

What is your opinion about this?

Figure 3. Black and White Marbles Task.

\subsection{INTERVIEWS}

I carried out the interviews with students individually in a room away from the rest of the class. The student sat next to me and I read the problems aloud. With student permission, the interviews were audio-recorded for analysis and notes were made at the end of each interview of non-verbal behaviours during the interview. Each interview was about 40 minutes long. Paper, pencil and calculator were provided for the students.

About five minutes was spent in making the student feel at ease before introducing the tasks. Non-threatening personal questions as well as questions about favourite classroom activities were asked. It was stressed that the session was not a test and that what was required was for the student to explain as fully as possible the thought processes he or she used to arrive at an answer. Reassurance about confidentiality and anonymity of the interview data was given.

Although I followed a written interview protocol, the flexibility of the interview method allowed me to repeat the question or to rephrase it in a slightly different way in cases where a student seemed to misunderstand a question.

\subsection{ANALYSIS OF DATA}

Thematic analysis (Braun \& Clarke, 2006) was used to analyse the interview data in my study. The phases of data analysis involved familiarizing myself with the data, generating initial codes, searching for themes, and reviewing, defining and naming these themes.

The analysis indicated that the students used a variety of strategies for solving the problems. The data also revealed that many of the students held beliefs and used strategies based on prior knowledge and experience which could potentially inhibit their development of formal probability ideas.

\section{RESULTS AND DISCUSSION}

Based on previous research (Shaughnessey, 1992; Watson, 2006) I created a three-category rubric to describe the results. The three categories in the rubric are: non-statistical, partialstatistical, and statistical. The non-statistical responses were based on beliefs and experiences while the students using the partial-statistical responses applied rules and procedures inappropriately or referred to intuitive strategies.

Item 1 - Coin task In contrast to earlier studies (Fischbein \& Schnarch, 1997; Kahneman \& Tversky, 1972), none of the students' responses was considered statistical on Item 1. To be coded as statistical, a response needed to include a discussion of probability of getting a head or tail and what might happen in sequences of tosses over the long run. For example, students could suggest that it is easier for the 10 flips to deviate from $50 \%$ to $80 \%$ because that requires only three 'extra' heads above the average; with 50 tosses it would require 15 'extra' heads.

Students with Item 1 responses in the non-statistical category thought that the flipping of coins depends on luck or how one tosses the coin. This is reflected in the following responses:

Eh ... as I said before ... because when you throw each time the coin comes head or tail or

tail or head. She will throw the coin in one direction so she will get $\mathrm{HHH}$, when she will 
change in another direction she will get all tails. So it will depend on how fast you throw and how fast the coin swings.

This flipping of coins depends on luck; if a person ... is a lucky person. then he will be able to have heads.

Students using the partial-statistical responses applied rules inappropriately or based their reasoning on intuitions such as the equiprobability bias (Lecoutre, 1992). For example, one student responded that Shelly is more likely to get $80 \%$ "because she gets 40 ". She simply calculated $80 \%$ of 50 , getting an answer of 40 . Another student used additive thinking, the bigger the better:

Yeah, Oh ... would be Shelley. Because Shelley's amount comes to 50; Anita does it only

10 times. Oh ... Shelley because she does more flips. She got more chance to get $80 \%$.

It may be that the student did not understand the question, and preferred to perform arithmetic operations on the numbers given in the problem. The students using the equiprobability bias responded that both Shelly and Anita will get the same number of heads, because heads and tails were equally likely. Even repeated probing by myself did not induce any consideration for sample size. Two students even altered the problem to align it with their views, that both had the same chance.

I: Can you explain your answer?

S2: Because a coin has two sides -- only heads or tails. One tosses it 10 times or 100 times, it makes no difference.

I: $\quad$ So you think that both will get $80 \%$ or more heads?

S2: $80 \%$ or more heads, no [laughs]. Not $80 \%$. They will be getting $50 \%$ or more heads.

I: Can you say why?

S2: Because the chances of heads and tails is half. So it will be $50 \%$.

Item 2 - Advertisement task There was not much evidence of students integrating theoretical and experimental views of probability on this task. Strong influences of religious beliefs were apparent when students were asked to comment on the advertisement. Even when challenged about how the people placing the advertisement could make money, the students could not see that roughly half the babies born would be girls and half would be boys. Anyone can expect to be right in half the number of cases just by guessing. Even if predictions are made incorrectly, some will not bother to complain, and a clear profit can be made on $50 \%$ of the all the payments sent in. The powerful nature of their religious beliefs is reflected in the following response:

As I have told you before that God creates all human beings. He is the one who decides whether a boy is born or a girl is born. Unless and until like now they have made a machine if one is pregnant and they can go there and they tell you whether the baby is a girl or a boy. But they can't tell until the baby is 8 months old. So that it means that God created like that before we can't tell that the baby is a male or a female.

Three students who referred to previous experience when commenting on the advertisement said that the advertisement was placed just to earn money. When asked to explain their thinking, students talked about businesses putting advertisements to sell their products. One student thought that this problem was mainly concerned with a doctor charging a \$20 consulting fee to inform the parents of the sex of their unborn baby. The powerful nature of everyday reading strategies of skimming and using the context or knowledge of the world to support comprehension are reflected in the following interview:

S3: The doctor may be charging $\$ 20$.

I: This could be any person charging $\$ 20$ for predicting the sex of the baby. What is your opinion about this advertisement?

S3: No.

I: What do you mean by "No"?

S3: Because it's a bad thing. They change the sex.

I: They are not changing the sex, they are just predicting the sex of the baby by looking at the handwriting. So what's your opinion about it now?

S3: That when anything goes wrong, then they must know the handwriting of the person. 
The student had an idea that the problem concerned determining the sex of the baby but then seemed to associate it with notions of childbirth difficulties.

Item 3 - Black and white marbles task Two students in the study showed a sound understanding of the ratio concept on this problem. They were not only able to say that age did not matter in chance games, but were also able to work out the appropriate probabilities for the marble task.

However, the data showed that in a number of cases students did not use a statistical model but based their reasoning on their cultural beliefs and experiences. Two common beliefs identified on this item related to causality and outcomes being controlled. Five students tried to seek a cause for an action. The students said that because Meena was older, she had more chance of pulling out a white marble. Others claimed that Ronit had more chance of choosing a white marble because she had more whites in her bag.

A few students missed the point of the question by focussing on whether the game was fair. This is reflected in this comment made by a student: "This is not a fair game; for this the game should be played by same aged people and there should be equal number of marbles in the box."

In addition to basing their thinking on beliefs, some students based their reasoning on cultural experiences. For example, one student explained why it was fair that the younger child Ronit had more marbles: "At my home I got three brothers so when my father gets two apples, then he gives one whole apple to my smaller brother and us two brothers, we get half each."

The prominence of the causality perspective such as 'younger one first' can be explained in terms of student experiences within the Fijian community. In everyday life, children learn mainly by observing what their parents and elders do and practising or imitating their behaviour themselves. Generally, the younger child is given the best of everything. For example, students may observe that parents and grandparents usually serve the younger children first. In the play situation, this is reflected in the older children giving the younger children the first turn. This is particularly evident in games such as snakes and ladders which require children to take turns. Hence, in this particular problem, the issue of Meena having more chance of pulling out a white marble because she is older became one of a cultural concern for fairness.

Rather than attending to given proportionality information (10 white and 20 black marbles versus 20 white and 60 black marbles), two students based their reasoning on previous sports experience. The following discussion illustrates this misunderstanding:

I: Now Meena says that the game is not fair because in Ronit's box there are more white marbles than in her box. What is your opinion about this?

S20: Eh ... So if you play a game, it should be equally in number.

I: What do you mean by equally?

S20: Like soccer: if you are playing, there should be 11 players a side. Then you will be able to have a win eh. So here it is like marble it is 10 white and 20 black marbles. So the game should be equally.

It is clear that this student, instead of performing correct proportionality calculations, used his prior sports experience to deal with the task.

In addition, the data show that everyday reading strategies of skimming and using the context or knowledge of the world to support comprehension are insufficient for reading probabilistic English. In some cases, the meaning I intended in this problem was not that constructed by the students and used as a basis for their responses. Rather than attending to proportionality information, some students based their reasoning on everyday language skills. The ordinary expectation of the way words are put together in English led students to assume that the phrase 'at the same time' implies some action. For instance, one student interpreted the problem as a game involving competition and a winner. The findings are similar to those reported by Winsor (2007) and Kazima (2006). These researchers noted many problems that can arise in the areas of statistical vocabulary and syntax, problems that exist for native English speakers, but are more extreme for students who speak English as a second language. 


\section{REFLECTIONS, IMPLICATIONS, AND CONCLUSIONS}

\subsection{REFLECTIONS}

The findings discussed in this paper show that often students' explanations are not based on statistical principles but on their own readily-accessed beliefs and everyday experiences. In a number of cases, students based their reasoning on their beliefs about coins (luck, control). The view that an outcome is due to luck or control is a widespread belief within the Fijian community. Students mentioned luck associated with sighting pigeons when asked to elaborate on luck. Bad luck was associated with owls crying at nighttime. These examples reveal the extent to which belief in luck permeates the thinking of Fijian students. Thus, it is not surprising that these formed an important component of these students' explanations.

In addition to reasoning on the basis of control and luck, some students based their explanations on their religious beliefs. The students considered that God controls everything that happens in the world. For the advertisement regarding the sex of a baby (Item 2), three students thought that no predictions could be made because the sex of the baby depends on God; this concurs with results of studies by Amir and Williams (1999). However, it may be problematic if students' prior experiences and beliefs conflict with the probability concepts that teachers are trying to teach them.

In spite of the importance of relating classroom statistics to the real world, my findings indicate that students frequently fail to connect what they learn at school with situations in which it is needed. For instance, while students could obtain the theoretical probability for rolling a die (Sharma, 1997), they had difficulty estimating probabilities for a real-life situation (such as Item 2). In fact, none of the students used theoretical or experimental interpretations for this problem. One explanation for this could lie in students' experiences of statistics in the classroom. Rich statistical situations from everyday culture are rarely found in the statistics classroom; hence, students see little connections between these two cultures. Clearly, the results support claims made by Gal (2002) and Nasir et al. (2008) that learning for students is situation specific and thatconnecting students' everyday contexts to academic statistics is not easy.

It must be noted that the limited use of statistical thinking on the items may be a consequence of a lack of emphasis on variation (Item 1) and experimental probability (Item 2) in the classroom and curricular materials. The school curriculum up to this level suggests the teaching of statistics as part of mathematics, and the examples provided are based on finite sample spaces for which it is possible to list, count and compare outcomes explicitly. Moreover, students are not used to explaining their thinking in the classroom, or perhaps they had difficulty in explaining their reasoning in detail due to language difficulties. Students in Fiji are influenced by a culture of obedience, it may be possible that the students feared that if they did not respond they would not be considered good students by their teacher and accordingly their class results could be affected. Although students were told that they could explain their thinking in their mother tongue, none of the students used this opportunity. At home, students mostly use their mother tongue, often considered pre-literate (Shameem, 2002), and hence students did not consider their vernacular appropriate in the school context.

To be able to utilise the information given in Item 2, one has to have a critical stance and positive attitudes (Gal, 2002). However, in Fiji students are taught not to question authority and defer to senior people's opinion, and explicit teaching of critical thinking is not the norm. The teacher is often viewed as a person of rich knowledge, respected by many in the community.

The responses certainly raise further questions. Is there a weakness in the wording of the tasks in that they are completely open-ended and do not direct students to draw on other relevant knowledge? Students have to assume that heads and tails are equally likely (Item 1). Perhaps including cues such as 'fair' in the question would have aided in the interpretation of this question. Are students using a subjectivist perspective? Although we view the flip of a coin and throw of a die as random, deterministic physical laws govern what happens during these trials. We can imagine throwing a coin in a way that we can predict the outcome (and some people can actually do this). Maybe students are working from a deterministic perspective. 
Students' tendency to apply rules to Item 1 could be explained in terms of their mathematical experiences. In the classroom, students usually approach a problem by searching for a rule that identifies the topic for that question, what is given, and what is being sought. Such learning experiences may have led students to tackle the task by performing calculations rather than using a conceptual understanding of the context.

Overall, the findings provide evidence of the assumptions of Bishop (2002) and Meaney (2002) that formal statistics education may produce cultural conflicts between students' everyday culture and the culture of statistics. As such, the results from this study have implications for teaching and research.

\subsection{IMPLICATIONS FOR TEACHERS AND RESEARCHERS}

The findings from my study indicate that a majority of students did not have a clear idea of the probability constructs embedded in the three tasks. The open-ended nature of the tasks, the lack of direction given, and the cultural norm of following teachers' instructions may have influenced how students explained their understanding. Some students in this sample clearly had difficulty explaining their thinking explicitly. Despite these limitations, the findings have several implications for teachers and research.

Firstly, when beginning instruction in statistics, it is important for teachers to be aware of the cultural background of their students. Once the initial understanding has been explored, it is crucial for teachers to build on students' ideas. Teachers can assess their students' understanding through individual interviews, though this may be difficult time-wise. However, teachers can get an insight into students' learning by interviewing just a couple of students and generalising to the class. Teachers could also make more use of paper and pencil tests in which students are asked to explain their thinking.

It appears that learning about statistical constructs is a complex process and requires explicit planning, teaching and assessment. Furthermore, teachers could do more to integrate cultural and domain knowledge in the classroom. Such integration would allow students to construct meanings from data and build the foundation for an understanding of these ideas.

One way to bridge the gap between school mathematics and everyday context is to address issues within society that directly impact students' lives. A good example in Fiji is the study of 'Fiji Sixes'. This is a lotto game played all over the country, mostly by adults, by choosing six numbers between 1 and 45. Students could discuss information about the game, in particular, popular beliefs about the role of lucky numbers. The next step could be to model the odds of winning and the final step to interpret the results. These processes and class discussions might lead students to reconsidering their own ideas about chance.

Teachers should be sensitive to the possible effects of cultural differences, in particular, religious ones. Fijian students learn that questioning religion in any form is completely inappropriate and seen as a challenging. A number of students in my study drew upon their religious beliefs when resolving their thinking. Fijian cultural influences, such as that God decides the sex of a baby, can be addressed during the teaching and learning process to help students construct views of probability that promote and enhance their statistical thinking. Students benefit from having a teacher who is a 'culture broker' (Neel, 2011), who can help students move between the two settings.

The use of open-ended tasks gave students the opportunity to display their understandings in both school (Item 1) and everyday contexts (Item 2). However, there were issues with the wording and format of tasks, and several students had difficulty interpreting Item 2. Questions can be structured to allow for varying degrees of difficulty, to build up interest cumulatively, or to introduce a striking idea or context. Such issues could be addressed in future research.

The participants in my study were a fairly small, non-random sample from one school. Thus, the findings - in particular, the number of students who thought about statistics in a particular way- may or may not generalize to the population of secondary school students as a whole in Fiji. There is a need for more research with larger and random samples with different backgrounds to determine how common these ways of thinking are in the general population. 
Furthermore, as noted earlier, the results reported in this paper were part of a larger study focusing on many areas of statistics. Since there had been few studies that focused on statistics and probability outside Western countries (Shaughnessy, 1992), it was not apparent when this study was conducted that the questions discussed in this paper would be as rich and interesting as they were. Now that the cultural aspects described in this paper have been identified as possible areas of concern, there is opportunity for more qualitative research focused on a deeper cultural understanding of students' thinking about statistics and probability concepts.

My study focused on students' thinking about statistics before they had studied it as a part of their senior secondary course work. This suggests another opportunity for research that examines students' thinking about these concepts after they have completed their senior secondary coursework. In particular, it would be interesting to examine the effects of different types of instruction on students' thinking in these areas. This would help clarify cultural issues as well as ambiguous effects of teaching.

In my study, while pupils answered some questions with reference to their statistical knowledge, they used their cultural knowledge on other items. It would be interesting to see how easily (or whether) students who argued on the basis of cultural knowledge on these questions could be persuaded to argue purely on the basis of the numerical data. Pratt $(2005, \mathrm{p}$. 185 ) argues that if "children have seen the lack of explanatory power of their own ideas they would reconsider recently learned knowledge." Future research could incorporate this into the interview procedure to explore this issue in more depth across different contexts.

The most critical participant in any learning environment is the teacher. A number of researchers have highlighted the importance of teachers' own knowledge of statistics (Garfield \& Ben-Zvi, 2008; Jones et al., 2007). With respect to culture, Greer and Mukhopadhyay (2005) caution us that statistics is often introduced with minimal regard to historical and cultural context, despite the fact that it is a cultural construction historically linked to religious issues. Teacher educators should be aware not only of students' knowledge of statistics and probability but also of their understanding of cultural knowledge. Research efforts at this level could also be useful; through cultural studies we may gain some perspective on the forces and issues that have contributed to change in statistics education and suggest fruitful approaches and solutions.

\subsection{CONCLUDING THOUGHTS}

I hope that the findings reported in this paper will generate more interest in research with respect to students' cultural ideas and cultural differences that may impact student learning. There is also the problem of documenting the challenges and difficulties that researchers face in the process of conducting international studies and the role of cultural factors in research activities and results. I believe we need to look for new ideas and develop more collaborative and cross-cultural research between practitioners and researchers if we are to improve outcomes for all our students. Research methods developed in one cultural setting may not be appropriate in another cultural context. Teachers, curriculum developers and researchers can work together to find better ways to help all students develop statistical literacy.

\section{REFERENCES}

Amir, G., \& Williams, J. (1999). Cultural influences on children's probabilistic thinking. Journal of Mathematical Behavior, 18(10), 85-107.

Bishop, A. J. (1988). Mathematical enculturation: A cultural perspective on mathematics education. Dordrecht, Germany: Kluwer.

Bishop, A. J. (2002). Critical challenges in researching cultural issues in mathematics education. Journal of Intercultural Studies, 23(2), 119-131.

Bourdieu, P. (1984). Distinction: A social critique of the judgement of taste. Cambridge, MA: Harvard University Press.

Braun, V., \& Clarke, V. (2006). Using thematic analysis in psychology. Qualitative Research in Psychology, 3(2), 77-101. 
Cao, Z., Forgasz, H., \& Bishop, A. (2007). Doing surveys in different cultures: Difficulties and differences- A case from China and Australia. In B. Atweh, A.C. Barton, M. C. Borba, N. Gough, C. Keitel, C. Vistro-Yu \& R. Vithal (Eds.), Internationalisation and Globalisation in Mathematics and Science Education (pp. 301-319). Dordrecht, The Netherlands: Springer.

Chiesi, F., \& Primi, C (2009). Recency effects in primary-age children and college students. International Electronic Journal of Mathematics Education, 4(3), 259-274.

Clark, M. (2001). Cross-cultural issues with students from the South Pacific. Australian Mathematics Teacher, 57(1), 17-20.

Confrey, J., \& Kazak, S. (2006). A thirty-year reflection on constructivism in mathematics education in PME. In A. Gutiérrez \& P. Boero (Eds.), Handbook of research on the psychology of mathematics education: Past, present and future (pp. 305-345). Rotterdam: Sense Publishers.

Ernest, P. (2007). Epistemological issues in the internationalization and globalization of mathematics education. In B. Atweh, A.C. Barton, M.C. Borba, N. Gough, C. Keitel, C. Vistro-Yu \& R. Vithal (Eds.), Internationalisation and globalisation in mathematics and science education (pp. 19-38). Dordrecht, The Netherlands: Springer.

Fijian Ministry of Education, Women, Culture, Science and Technology (1994). Primary mathematics prescriptions. Suva: Curriculum Development Unit.

FijiGuide (2014). The People. [Online: http://fijiguide.com/page/the-people]

Fischbein, E., Nello, M. S., \& Marino, M. S. (1991). Factors affecting probabilistic judgements in children and adolescents. Educational Studies in Mathematics, 22(6), 523-549.

Fischbein, E., \& Schnarch, D. (1997). The evolution with age of probabilistic, intuitively based misconceptions. Journal for Research in Mathematics Education, 28(1), 96-105.

Gal, I. (2002). Adults' statistical literacy: Meanings, components, responsibilities. International Statistical Review, 70(1), 1-24.

Garfield, J. B., \& Ben-Zvi, D. (2008). Preparing school teachers to develop students' statistical reasoning. In C. Batanero, G. Burrill, C. Reading \& A. Rossman (Eds.), Joint ICMI/IASE Study: Teaching Statistics in School Mathematics, Challenges for Teaching and Teacher Education. Proceedings of the ICMI Study 18 and 2008 IASE Roundtable Conference

Greer, G., \& Mukhopadhyay, S. (2005). Teaching and learning the mathematization of uncertainty: Historical, cultural, social and political contexts. In G. A. Jones (Ed.), Exploring probability in school: Challenges for teaching and learning (pp. 297-324). New York: Springer.

Jones, G. A., Langrall, C. W., \& Mooney, E. S. (2007). Research in probability: Responding to classroom realities. In F. K. Lester, Jr. (Ed.), Second handbook of research on mathematics teaching and learning (pp. 909-955). Reston, VA: National Council of Teachers of Mathematics.

Kahneman, D., \& Tversky, A. (1972). Subjective probability: a judgment of representativeness. Cognitive Psychology, 3(3), 430-454.

Kazima, M. (2006). Malawian students meaning for probability vocabulary. Educational Studies in Mathematics, 64(2), 169-189.

Lecoutre, M. (1992). Cognitive models and problem spaces in purely random situations. Educational Studies in Mathematics, 23(6), 557-568.

Lesser, L., \& Winsor, M. (2009). English language learners in introductory statistics: Lessons learned from an exploratory case study of two pre-service teachers. Statistics Education Research Journal, 8(2), 5-32. [Online: http://iase-web.org/documents/SERJ/SERJ8(2)_Lesser_Winsor.pdf ]

Lubienski, S. (2002). Research, reform, and equity in US mathematics education. Mathematical Thinking and Learning, 4(2/3), 103-125.

Meaney, T. (2002). Symbiosis or cultural clash? Indigenous students learning mathematics. Journal of Intercultural Studies, 23(2), 167-187.

Ministry of Education. (2007). The New Zealand Curriculum. Wellington: Learning Media. 
Nasir, N. S., Hand, V., \& Taylor, E. V. (2008). Culture and mathematics: boundaries between 'Cultural' and 'Domain' knowledge in the mathematics classroom and beyond. Review of Research in Education, 32(1), 187-240.

National Council of Teachers of Mathematics (NCTM) (2000). Principles and standards for school mathematics. Reston, VA: National Council of Teachers of Mathematics.

Neel, K. (2011). Factors that motivate Aboriginal students to improve their achievement in school mathematics. In D. J. Brahier \& W. R. Speer (Eds.), Motivation and disposition: Pathways to learning mathematics. (pp. 113-126). Reston, VA: National Council of Teachers of Mathematics.

Polaki, M. V. (2002). Using instruction to identify key features of Basotho elementary students' growth in probabilistic thinking. Mathematical Thinking and Learning, 4(4), 285-314.

Pratt, D. (2005). How do teachers foster students' understanding of probability? In G. A. Jones (Ed.), Exploring probability in school: Challenges for teaching and learning (pp. 171-189). New York: Springer.

Reid, A., \& Petocz, P. (2007). Internationalisation as an orientation for learning and teaching in mathematics. In B. Atweh, A. C. Barton, M. C. Borba, N. Gough, C. Keitel, C. Vistro-Yu, $\&$ R. Vithal (Eds.), Internationalisation and globalisation in mathematics and science education (pp. 247-267). Dordrecht, The Netherlands: Springer.

Rossman, A., Chance, B., \& Medina, E. (2006). Some important comparisons between statistics and mathematics, and why teachers should care. In G. Burrill \& P.C. Elliot (Eds.), Thinking and reasoning with data and chance (pp. 323-333). Reston, VA: National Council of Teachers of Mathematics.

Schield, M. (2010). Assessing statistical literacy: take CARE. In P. Bidgood, N. Hunt, \& F. Jolliffe (Eds.), Assessment methods in statistical education: An international perspective (pp. 133-152). New York: John Wiley \& Sons Ltd.

Shameem, N. (2002). Classroom language use in a multilingual community - the Indo-Fijians in Fiji. Journal of Intercultural Studies, 23(2), 267-284.

Sharma, S. (1997). Statistical Ideas of High School Students: Some Findings from Fiji. Unpublished doctoral thesis. Waikato University, Hamilton, New Zealand

Shaughnessy, J. M. (1992). Research in probability and statistics: Reflections and directions. In D. Grouws (Ed.), Handbook of research on mathematics teaching and learning (pp. 465494). New York: Macmillan.

Shaughnessy, J. M. (2007). Research on statistics learning and reasoning. In F. K. Lester, Jr. (Ed.), Second handbook of research on mathematics teaching and learning (pp. 957-1009). Reston, VA: National Council of Teachers of Mathematics.

Tishkovskaya, S., \& Lancaster, G. (2012). Statistical education in the 21st century: a review of challenges, teaching innovations and strategies for reform. Journal of Statistics Education, 20(2), 1-24.

[Online: http://www.amstat.org/publications/jse/v20n2/tishkovskaya.pdf ]

Truran, K. M. (1994). Children's understandings of random generators. In C. Beesey \& D. Rasmussen (Eds.), Mathematics without Limits: Proceedings of the 31st Annual Conference of the Mathematical Association of Victoria (pp. 356-362). Melbourne: Mathematics Association of Victoria.

von Glasersfeld, E. (1993). Questions and answers about radical constructivism. In K. Tobin (Ed.), The practice of constructivism in science education (pp. 24-38). Washington, DC: American Association for the Advancement of Science.

Vygotsky, L. (1978). Mind in society: The development of higher psychological processes. Cambridge, MA: Harvard University Press.

Watson, J. M. (2006). Statistical literacy at school: Growth and goals. Mahwah, NJ: Lawrence Erlbaum

Winsor, M. S. (2007). Bridging the language barrier in mathematics. Mathematics Teacher, 101(5), 372-378.

Zimmermann, G. M., \& Jones, G. A. (2002). Probability simulation: what meaning does it have for high school students? Canadian Journal of Science, Mathematics and Technology Education, 2(2), 221-236. 
SASHI SHARMA

Department of Mathematics, Science and Technology Education The University of Waikato

Hamilton

New Zealand 